\title{
Idiomatic expressions and anaphoric reference in functional discourse grammar
}

\author{
Les expressions idiomàtiques i la referència anafòrica \\ en la gramàtica funcional discursiva
}

\section{Evelien Keizer}

University of Vienna. evelien.keizer@univie.ac.at

Received: 17/03/2018. Accepted: 29/06/2018

\begin{abstract}
This paper deals with a special kind of anaphoric relation involving reference by or to a component part of a non-decomposable idiom. It is argued that, unlike generally assumed, such references are not necessarily stylistically deviant or grammatically marked, but that various systematic and productive patterns of use can be identified. On the basis of corpus data, and using the framework of Functional Discourse Grammar, a theoretical linguistic analysis of each of these patterns is proposed which reflects the linguistic processes involved in their production and interpretation, captures their systematicity and productivity, and goes some way towards explaining the cognitive cost and communicate gain involved in their use.
\end{abstract}

Keywords: English idioms; idiom variation: anaphoric reference; context; Functional Discourse Grammar.

Resum: Aquest treball se centra en un tipus especial de relació anafòrica que consisteix en la referència efectuada mitjançant una part, o a una part, d'una expressió idiomàtica. S'hi posa de manifest que, contràriament al que se suposa generalment, aquestes referències no estan necessàriament marcades estilísticament o gramaticalment, sinó que responen a diversos patrons productius. A partir de dades de corpus i dins del marc de la gramàtica funcional discursiva es presenta una anàlisi amb base teòrica de cadascun d'aquests patrons. L'anàlisi en reflecteix els processos de producció i interpretació, en dona compte de la sistematicitat i productivitat i presenta una proposta explicativa del cost cognitiu i els avantatges comunicatius que impliquen l'ús d'aquests patrons.

Paraules clau: expressions idiomàtiques en anglès; variació en les expressions idiomàtiques; referència anafòrica; context; gramàtica funcional discursiva.

》) Keizer, Evelien. 2018. "Idiomatic expressions and anaphoric reference in functional discourse grammar". Quaderns de Filologia: Estudis Lingüistics XXIII: 177195. doi: 10.7203/qf.23.13527 



\section{Introduction}

This paper will be concerned with the description and analysis of what is often regarded as a "deviant" kind of anaphoric relation, namely that in which a component part of a non-decomposable (non-isomorphic, non-combining) idiom (motivated or unmotivated) is either referred to or is itself used to refer to a discourse referent. Some examples are given in (1):

(1) a. Everybody wants to bring home the bacon. The difference is this bacon can blow up the world. (NOW, Huffington Post, US) [reference to part of a motivated non-decomposable idiom]

b. The win just might be the impetus the Jays need as they improved to 8-17 and just avoided the worst March/April start in club history (7-15 in 1979 and 2004 takes that cake) (NOW, Toronto Sun, CA) [reference by part of an unmotivated non-decomposable idiom]

Although it is widely recognized that component parts of decomposable (isomorphic, combining) idioms (e.g. to grasp the nettle, to spill the beans) readily allow for syntactic variation and manipulation (including anaphoric reference to or by one of their component parts) (Nunberg, Sag \& Wasow, 1993; Langlotz, 2006; Vega, 2007), in the case of non-decomposable idioms (like those in (1)) such manipulation is typically dismissed as "wordplay" (i.e. as highly conspicuous and context-dependent; e.g. Langlotz, 2007: 194-197, 202-203; see also Dik, 1992: 255).

In the present paper, data from two large corpora of English (the Corpus of Contemporary American English (COCA; Davies, 2014) and the News on the Web Corpus (NOW; Davies, 2016)) will be used to show that anaphoric reference by or to a component part of a non-decomposable idiom is, in fact, systematic, and that various productive patterns can be identified. Using the theory of Functional Discourse Grammar (FDG; Hengeveld \& Mackenzie, 2008), and in particular Keizer's (2016) treatment of different types of idioms, an analysis will be offered of the discourse-pragmatic, semantic and syntactic properties of these different patterns of anaphoric reference, as well as of their interaction with the context. The proposed analysis will also go some way in accounting for the various degrees of cognitive effort involved 
in producing and processing these different patterns of anaphoric reference.

After a brief overview of some relevant aspects of idioms (in particular transparency and decomposability) in Section 2, some of the attested patterns of anaphoric reference by and to component parts of non-decomposable idioms will be described (Section 3). This will be followed by a general characterization of FDG and an indication of how the theory deals with different types of idioms (Section 4). In Section 5, an FDG analysis will be provided of the different types of anaphoric reference discussed in the paper. Section 6 presents the conclusion.

\section{Idiom variation}

It has long been recognized that idioms are a highly heterogeneous group, not only in terms of form (phrase or clause, kind of phrase, number and kind of open positions, etc.), but also in terms of their semantic features and syntactic behaviour. Thus, whereas all idioms are conventionalized multi-word expressions whose idiomatic meaning is not predictable from the literal meaning of their separate parts, they vary in terms of transparency (i.e. "the ease with which the motivation for the use [...] can be recovered" (Nunberg et al., 1994: 496)) and compositionality (i.e. the extent to which specific aspects of the idiomatic meaning can be related to their component parts (e.g. Nunberg et al., 1994; Langlotz, 2006; Vega, 2007)). In turn, it has been argued that different types of idioms vary with regard to their degree of syntactic flexibility. In this section, we will first look at three types of idiom that have been distinguished (Section 2.1); subsequently, we will briefly consider the notion of wordplay (Section 2.2).

\subsection{Different classes of idioms}

In recent literature on idiom variation and idiomatic creativity, three broad classes of idioms have been distinguished, on the basis of two parameters: (1) transparency (or motivation) and (2) semantic decomposability (or isomorphism) (e.g. Langlotz, 2006: 128-130).

In the class of unmotivated, semantically non-decomposable idioms (Nunberg et al.'s (1994) “idiomatic phrases"), we find idioms like to kick the bucket and to take the biscuit/cake. What these idioms have in 
common is that, even for a speaker familiar with their conventionalized meaning, it is difficult to see where this conventionalized meaning comes from, since there seems to be no relation between the component parts of the "literal scene" evoked by the idiom (Langlotz, 2006: 185194) and aspects of its idiomatic meaning. As a result, it is difficult to recognize the contribution made by the separate components to this idiomatic meaning; in the case of to take the biscuit, for instance, there is nothing in the idiomatic meaning that can reasonably be related to the notion of a biscuit.

Idioms like these are generally assumed to resist any kind of manipulation: they do not, for instance, allow for modification (*to kick the empty bucket ${ }^{1}$, lexical substitution (*to kick the pail), nominalization and passivization (*Tom's kicking of the bucket, *The bucket was kicked by Tom), pluralization and quantification (e.g. *Her parents kicked the/ both buckets) or anaphoric reference (*Peter kicked it, too).

At the other end of the scale, we find the class of motivated decomposable idioms (Nunberg et al.'s (1994) “idiomatically combining expressions"), such as to spill the beans or to grasp the nettle. In these idioms, there is not only a clear relation between the idiomatic meaning of the expression and the literal scene evoked, but, in addition, we can see the contribution that each of the components makes to the idiomatic meaning (in the case of to grasp the nettle: grasp $=$ tackle, nettle $=$ problem).

Due to their compositionality, decomposable idioms are subject to the normal rules of grammar, allowing for modification, nominalization, passivization, pluralization, quantification and anaphoric reference (Nunberg et al., 1994; Jackendoff, 2002; Langlotz, 2006; Keizer, 2016) $)^{2}$. Some examples are given in (2):

(2) a. And then comes the inevitable spilling of the beans, ... (COCA, fiction) [modification, nominalization]

b. Jones spilled some beans on the new series ... (NOW, Wales Online, GB) [quantification]

\footnotetext{
${ }^{1}$ As pointed out by Keizer (2016: 993-997), however, this very much relies on the type of modification involved.

${ }^{2}$ Although not for clefting, nor, typically, for substitution (Keizer, 2016: 998).
} 
Finally, there is a third class of idioms, such as to open the floodgates, to throw in the towel and to hit the ceiling, that are non-decomposable, but nevertheless motivated. In these idioms, the literal scene evoked by the idiom (e.g. "to open the floodgates") is clearly associated with their idiomatic meaning (e.g. "to suddenly make it possible or easier for things to happen"). At the same time, however, it is not clear how the component parts of the idiom (the verb open and noun phrase the floodgates) contribute to its overall meaning. In terms of syntactic behaviour, motivated non-decomposable idioms resemble unmotivated non-decomposable idioms, except that they allow for certain forms of modification (to open the social media floodgates), as well as for (institutionalized) substitution (e.g. to open the floodgates/sluices, to throw in the towel/sponge; see Nunberg et al., 1994: 504; Keizer, 2016).

\subsection{Systematic variation vs. wordplay}

Although non-decomposable idioms, as we have seen, are generally assumed to be highly restricted when it comes to their syntactic behaviour, this does not mean that these idioms do not allow for any kind of variation. However, when they are manipulated, we are, according to Langlotz (2006: 194-205), likely to be dealing with idiomatic wordplay, i.e. idiom variation which "goes beyond the conventional and characteristic modelling function of idioms", and which "is exploited as a resource for stylistic and poetic effects" (Langlotz, 2006: 197). Such idiomatic wordplay comes in different degrees, and can be measured by applying three criteria (Langlotz, 2006: 202-203):

1. Stylistic markedness/conspicuousness: the idiom is adapted "in a striking or stunning way";

2. Ambiguity: both the literal meaning and the idiomatic meaning "are strongly implicated";

3. Context dependency: speakers can only be assumed to make sense of the adapted form of an idiom "in the usage-context".

Although it is certainly true that in many cases variations of non-decomposable idioms fulfil one or more of these criteria, the notion of wordplay does not apply equally well to all types of idiom variation. Thus, passivization and nominalization always yield a semantically 
conspicuous result, while substitution often leads to ambiguity, ${ }^{3}$ as well as to context-dependency (in the sense that the adapted form of the idiom is only recognizable as an idiom in a specific context; see Langlotz, 2006: 202). In the case of anaphoric reference by or to a component part of a non-decomposable idiom, however, the evidence for wordplay is less convincing. Thus, as we will see, this kind of syntactic manipulation does not necessarily result in a stylistically striking expression, nor does it always activate both levels of meaning. Furthermore, it is only in some cases that context dependency, as understood by Langlotz, plays a role. In other words, anaphoric reference by or to part of an idiom need not involve wordplay.

Moreover, this use of this kind of anaphoricity raises a range of other questions. For instance, if the idiom is non-decompositional, and its separate parts are not (metaphorically) associated with a particular aspect of its idiomatic meaning, then what is it that the pronoun refers to? In other words, if cake in to take the cake does not make a contribution to the idiomatic meaning, then how is it that (unlike what is commonly assumed) we can either refer back to this element or use it to refer to a discourse referent (as in (1b))? And under which circumstances is such reference allowed? In order to answer these questions, let us have a closer look at some examples.

\section{Anaphoric reference by/to component parts of an idiom}

This section will provide a qualitative analysis of data collected from the two corpora (COCA, NOW). All examples include a non-decomposable idiom (motivated or unmotivated) which either contains an anaphoric expression or the antecedent of a following anaphoric expression (see example (1)). ${ }^{4}$ The patterns encountered have been classified on the basis of three parameters: (i) Anaphoric reference by or to part of

\footnotetext{
${ }^{3}$ This also holds for decomposable idioms; see Keizer (2016: 994-995).

${ }^{4}$ Examples were collected from 29 idioms (21 motivated, 8 unmotivated). Excluded from the sample were so-called recognitional uses of the demonstrative that, since the function of this particular use of the demonstrative is not to refer anaphorically, but to indicate familiarity (in this case with the idiom as a whole) (e.g. Chen, 1990; Diessel, 1999). An example is given in (i):

(i) “Turn that cheek," He said to me as I was praying, and of course I could see He was right. (COCA, fiction).
} 
an idiom; (ii) Anaphoric expression used in a compositional sentence or in an idiomatic expression; and (iii) Anaphoric reference to a previously introduced discourse topic or to an entity from the literal scene (or both). In what follows, the most important combinations of these parameters will be discussed in turn.

\subsection{Anaphoric reference by parts of a non-decomposable idiom}

Instances of non-decomposable idioms containing an anaphoric expression are relatively common. In these cases, the anaphoric expression is always used figuratively to refer to a previously introduced, identifiable discourse referent. Some examples are given in (4):

(4) a. We are accused of centralising FE. If we are going to be tarred with that brush then let's do something with it. (NOW, the National, GB) [motivated]

b. The win just might be the impetus the Jays need as they improved to 8-17 and just avoided the worst March/April start in club history (715 in 1979 and 2004 takes that cake). (NOW, Toronto Sun, CA) (= (1b)) [unmotivated]

Examples like these involve minimal adaptation of the literal scene: the idiomatic form is preserved and immediately recognizable; as such, these uses are not context-dependent. Neither are they stylistically very conspicuous ${ }^{5}$. Finally, the literal meaning is clearly backgrounded, which means that there is no ambiguity to be resolved. There is, in other words, no clear evidence of wordplay.

Nevertheless, it may be argued that resolving the anaphoric reference requires some extra cognitive effort, since it involves the reanalysis of a non-decomposable idiom into a decomposable one: where normally speaking the NP the cake in (4b) is not taken to contribute directly to the meaning of the idiom ("to do something that is annoying or surprising"), now it does: the cake in (4b) clearly equals "an annoying situation" (in much the same way that the beans in to spill the

\footnotetext{
${ }^{5}$ They may, however, be syntactically conspicuous, as in the following example, where a (fixed) plural anaphor refers back to a single situation.

(i) For us it's really important just to get that first goal. If we don't open those floodgates, we're not going to get going, ... (NOW, Chicago Tribune, US).
} 
beans refers to a secret). This extra cost involved, however, seems to be compensated for by both discourse-pragmatic (the anaphoric relation enhancing cohesion) and efficiency of expression (anaphoric reference and idiomatic predication combined in one construction).

\subsection{Anaphoric reference to part of an idiom}

\subsubsection{Reference to a previously introduced discourse entity}

Another type of anaphoric reference can be found in (5), where it is the antecedent that is part of an idiomatic expression, while the anaphor is part of a compositional sentence that displays little or no overlap (lexically or conceptually) with the preceding idiom.

(5) a. Everybody wants to bring home the bacon. The difference is this bacon can blow up the world. (NOW, Huffington Post, US) (=(1a)) [motivated]

b. And, perhaps best of all, it's going to be a family tradition. It's a family with quite a few of them, but this one takes the cake - and then has it donated. (NOW, Standard Freeholder, [unmotivated]

In these examples, reference is again made to a previously introduced discourse referent. In order for the reference to be successful, however, a process of inference is required. In (5a), for instance, this bacon refers to the US nuclear arsenal, which some groups want to protect, while others like to see it reduced. This, however, can be deduced neither from the literal, nor from the idiomatic meaning of the idiom: it is purely on the basis of the context (both the wider discourse context and the immediate co-text), that the antecedent can be established. At the same time, however, the immediate textual antecedent of the anaphoric expression is the NP the bacon. In this sense, examples like these can be regarded as wordplay, as they refer simultaneously at two levels: the level of discourse and the level of the literal scene. Thus, where the idiomatic meaning of the idiom is clearly relevant, this meaning does not play a role in the anaphoric reference, the main purpose of which is to enhance cohesion. In addition, by linking the idiom (with its highly relevant idiomatic meaning) back to a salient discourse referent clearly strengthens the main message of the text (by emphasizing in (5a) the high stakes involved, and in (5b) the family's generosity). 


\subsubsection{Reference to an entity in the literal scene}

There are also cases where the anaphoric expression is not used to refer to a previously introduced discourse entity, but solely to an element within the literal scene of a preceding idiom. This means that the literal meaning of the idiom, normally backgrounded, is now more highly activated, requiring a shift in focus of attention for both speaker and addressee. In many of these cases this does not, however, lead to any marked stylistic effect, as shown in the examples in (6):

(6) a. the child was hanging on by a thread, and that thread was beginning to unravel. (COCA, magazine) [motivated]

b. (from an article on alcohol consumption in the US in the 1790's) But it was the men in Independence Hall during the summer of 1787 who really took the cake, especially if $i t$ was drenched in bourbon. (NOW, Daily Beast, US) [unmotivated]

In these examples, the literal scene is clearly activated, while the extent to which the idiomatic meaning of the idiom is implicated by the anaphoric expression varies according to context. In (6a) both levels of meaning are implicated: the literal scene is manipulated, which in turn triggers a variation on the idiomatic meaning that makes sense in the context; reference, however, is unequivocally made to an element of the literal scene, and as such there is no ambiguity. In (6b), on the other hand, the anaphor does not really reinforce the idiomatic meaning of the idiom; instead the anaphoric expression functions as a cohesive device, linking the idiomatic meaning of the preceding idiom to the overall discourse topic.

\subsubsection{Creating a new, ad-hoc idiomatic expression}

Finally, there are those cases, illustrated in (7), that involve a minimal degree of variation on an existing, previously mentioned idiom, typically contrasting in one specific aspect (lexeme). In these cases, the high degree of textual overlap with the original idiom causes the expression to be immediately recognizable as an idiom, while the formal parallelism allows the reader to immediately identify the antecedent of the anaphoric pronoun. These idioms are, therefore, neither context- 
dependent $^{6}$, nor ambiguous. Moreover, as long as the variation in question is congruous with the literal meaning of the idioms, these instances of anaphoric reference are semantically inconspicuous.

(7) a. The DLC did bite a bullet on trade, or at least gnawed it. (COCA, magazine) [motivated]

b. Once the floodgates open, they cannot be closed. (NOW, The Guardian, UK) [motivated]

Examples like these have been so far been treated as cases of substitution (e.g. Glucksberg, 1993: 8; Langlotz, 2006: 39, 202). I would like to argue, however, that it is more than that, with the speaker creating a new, ad-hoc idiomatic expression, whose meaning the addressee is expected to be able to infer from the semantic relation between the two elements (the replaced and the replacing lexical item). In (7a), a new, non-decomposable idiom to gnaw the bullet is created ("to cautiously address an unpleasant situation"), while (7b) the ad-hoc idiom to close the floodgates ("to prevent things from happening") is introduced. Due to the minimal variation involved in these idioms, the obvious semantic relation between the two lexemes, and the unequivocal anaphoric reference of the pronouns they contain, producing and processing these variations may be expected to require relatively little cognitive effort.

\subsection{Summary}

From this preceding discussion, it is clear that wordplay is, indeed, a gradual notion, and that even in the case of non-decomposable idioms (both motivated and unmotivated), variation need not always be (highly) unconventional and unsystematic. Nevertheless, it may be argued that some of these cases require some extra cognitive effort, in particular those that require, for speaker and addressee alike, a process of reanalysis (from non-decomposable to decomposable idiom) or inference (a shift in focus from the idiomatic to the literal meaning of the

\footnotetext{
${ }^{6}$ For an alternative view, see Langlotz (2006: 202), who regards examples like those in (7) as context-dependent (and therefore as instances as of wordplay). Note, however, that the context dependency is merely the result of the presence of an anaphoric pronoun. The full form of the ad-hoc idiom (to gnaw the bullet) may be expected to be recognizable as an idiom also in isolation.
} 
idiom). The fact that these variations are nevertheless felicitous can be explained by the fact that their specific discourse-pragmatic functions (as cohesive or strengthening devices) and their efficiency (in relying on inference rather than explicit expression of meaning) outweigh the extra cognitive cost.

\section{Introduction to FDG}

\subsection{General characterization}

Functional Discourse Grammar is a typologically-based model of language use built on the principle that linguistic form - directly or indirectly - reflects communicative function. This means that FDG is organized in a top-down manner, taking the speaker's intention as the point of departure and from there working its way down to articulation. Another important characteristic of the model is that it analyses linguistic expressions in terms of four independent, but interactive, levels, dealing with pragmatics, semantics, morphosyntax and phonology. Finally, as part of a wider theory of verbal interaction, FDG systematically interacts with three other components: a conceptual, a contextual and an output component (Hengeveld \& Mackenzie, 2008: 1-12). This architecture reflects the idea that every linguistic communication starts with some communicative intention at the prelinguistic conceptual level. This information is subsequently fed into the grammatical component, where the operation of formulation converts it into interpersonal (pragmatic) and representational (semantic) representations. Next, the operation of encoding translates these into morphosyntactic and phonological representations, which, in turn, feed into the output component.

\subsection{Anaphoric reference}

In order to illustrate how FDG deals with reference, consider the sentence in (8) and its (simplified) FDG representations at the first two levels of analysis (as the only levels relevant to the discussion).

(8) Some students read books.

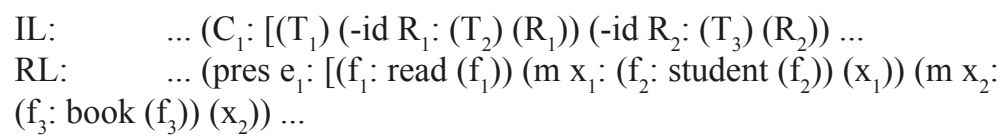


At the Interpersonal Level (IL), which deals with the pragmatic aspects of a linguistic utterance, we find a Communicated Content (C), consisting of two Referential Subacts (R), evoking the referents (or referent sets) realized as some students and books (i.e. the entities or sets of entities about which the author wants to say something) and three Ascriptive Subacts (T), evoking the properties "student", "book" and "read" (properties the speaker ascribes to the entities evoked). Both Referential Subacts have the feature [-identifiable], indicating that the Speaker does not assume the referent set to be recoverable or inferrable from the Contextual Component. The Representational Level (RL) deals with the semantic features of the expression, including tense and number. Here we find a predication $\left(\mathrm{e}_{1}\right)$, consisting of the verbal predicate read $\left(\mathrm{f}_{1}\right)$ and its two arguments $\left(\mathrm{x}_{1}\right.$ and $\left.\mathrm{x}_{2}\right)$, both plural $(\mathrm{m})$, and both headed by a nominal lexeme (the properties $\mathrm{f}_{2}$ and $\mathrm{f}_{3}$ ) restricting their denotation.

Let us now consider a simple case of anaphoric reference (note that only the two anaphorically related elements, some student and they, are represented):

(9) Some students were very interested. They read many books.

$$
\begin{array}{ll}
\text { IL: }\left(-i d R_{1}\right) & \left(+i d R_{2}\right) \\
\text { RL: }\left(\mathrm{x}_{1}:\left(\mathrm{f}_{1}: \text { student }\left(\mathrm{f}_{1}\right)\right)\left(\mathrm{x}_{1}\right)\right. & \left(\mathrm{x}_{1}\right)
\end{array}
$$

In (9) we once again see two Acts of Reference at the IL ( $R_{1}$ and $\left.R_{2}\right)$, since the same set of entities is referred to twice. At the RL, however, only one set of entities is denoted, as indicated by co-indexation of the relevant variable $\left(\mathrm{x}_{1}\right)$. Note in addition that in the case of pronominal anaphors, the representation unit $\left(\mathrm{x}_{1}\right)$ no longer has a lexical head, triggering the use of a pronoun at the Morphosyntactic Level.

\subsection{Idioms in FDG}

Keizer (2016: 1001-1006) proposes an analysis of idiom expressions in FDG that distinguishes the three classes described in Section 2, capturing the pragmatic and semantic differences between them, thus accounting for the differences in syntactic flexibility. What follows is a brief overview of the way in which the three classes of idioms can be represented in FDG. Once again use will be made of simplified representations at the first two levels of representation only. 
Decomposable idioms, such as to spill the beans, are analysed almost entirely like fully compositional constructions:

(10) He spilled the beans.

IL: $\left.\left(\mathrm{C}_{1}:\left[\left(\mathbf{T}_{1}\right)\left(+\mathbf{i d ~} \mathbf{R}_{1}:\left(\mathbf{T}_{2}\right)\right)\left(+\mathrm{id} \mathrm{R}_{2}\right)\right]\left(\mathrm{C}_{1}\right)\right)\right]$

RL: (past $\mathrm{e}_{1}$ : $\left[\left(\mathbf{f}_{1}: \operatorname{spill}\left(\mathbf{f}_{1}\right)\right)\left(\mathbf{m x _ { 1 }}:\left(\mathbf{f}_{2}\right.\right.\right.$ : bean $\left.\left.\left.\left.\left.\left(\mathbf{f}_{2}\right)\right)\left(\mathbf{x}_{1}\right)\right)\left(1 \mathrm{x}_{2}\right)\right]\left(\mathrm{f}_{1}\right)\right)\left(\mathrm{e}_{1}\right)\right)$

The most important non-predictable feature of these idioms is their conventional meaning, which, although motivated, cannot be derived from the literal meaning of the separate parts, and which must therefore be stored in the lexicon together with the fixed combination of representations given in $(10)^{7}$; i.e. together with the distinctive features of the idiom (given in bold): in this case, the presence of the two lexemes at RL, and the identifiability (at IL) and plurality (at RL) of the element the beans (represented as a Propositional Content, $\mathrm{p}$, since reference is made to a secret (a third-order entity) rather than to a concrete object; cf. Lyons, 1977: 442-7). Variation is, however, possible when required for communicative purposes. Moreover, there are no morphosyntactic restrictions on this type of idiom. Anaphoric reference, for instance, is unproblematic, since the component part the beans is analysed as a Referential Act at the Interpersonal Level $\left(\mathrm{R}_{1}\right)$, evoking an entity (the secret in question), and as a set at the RL $\left(\mathrm{p}_{1}\right)$, headed by the Property bean.

Non-decomposable idioms, however, are more irregular when it comes to their interpersonal and representational features, and, as a result, morphosyntactically more restricted. Consider the representation of the unmotivated non-decomposable idiom to kick the bucket in (11):

$$
\begin{aligned}
& \text { He kicked the bucket. } \\
& \text { IL: } \left.\left.\left(\mathrm{C}_{1}:\left[\left(\mathrm{T}_{1}\right)\left(+\mathrm{id} \mathrm{R}_{1}\right)\right]\left(\mathrm{C}_{1}\right)\right)\right]\left(\mathrm{A}_{1}\right)\right) \\
& \text { RL: } \left.\left(\text { past } \mathrm{e}_{1}:\left[\left(\mathrm{f}_{1}: \text { kick_the_bucket }\left(\mathrm{f}_{2}\right)\right)\left(1 \mathrm{x}_{1}\right)\right]\left(\mathrm{f}_{1}\right)\right)\left(\mathrm{e}_{1}\right)\right)
\end{aligned}
$$

In this case, the idiom as a whole is represented at the IL as one Ascriptive Subact ( $\mathrm{A}_{1}$; evoking the property "to die"), corresponding at the RL to a single, complex verbal predicate $\left(f_{1}\right)$. Since the component parts of the idiom do not function as separate units at the IL and RL, many morphosyntactic operations (modification, passivization, etc.) are

\footnotetext{
${ }^{7}$ Referred to by Keizer (2016) as ComPIFs (Combinations of Partially Instantiated Frames).
} 
blocked. This is also true for anaphoric reference: since by using the idiom, the speaker does not evoke an entity corresponding to the noun phrase the bucket, there is no entity to refer back to.

Motivated non-decomposable idioms are analysed in much the same way as unmotivated idioms. As shown in (12), the idiom is once again represented as a single Ascriptive Subact at the IL and as a fixed combination of lexemes at the RL (indicated by the extra square brackets). At the same time, however, the separate components are represented as separate units (e.g. $\mathrm{x}_{1}$, denoting a set of floodgates), reflecting the fact that the denotations of these elements contribute to the global meaning of the idiom. This also accounts for the fact that modification and substitution are (to some extent) allowed. Due to the absence of a Referential Act at the IL, however, anaphoric reference is excluded.

They opened the floodgates.

IL: $\left(\mathrm{C}_{1}:\left[\left(\mathrm{T}_{1}\right)(+\mathrm{id} \mathrm{R})\right]\left(\mathrm{C}_{1}\right)\right)$

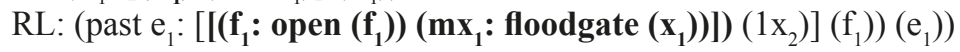

\section{Non-decomposable idioms and anaphoric reference in FDG}

As we have seen in the previous section, FDG offers a way of representing idioms that cannot only distinguish between the different classes of idioms, but which can also account for the difference in syntactic behaviour (flexibility) between them. At the same time, it will have become clear that these restrictions are too strict, at least with regard to the possibility of referring by or to parts of non-decomposable idioms, as this seems, under certain circumstances, to be allowed (Section 3). In this section I will now describe the steps that speakers and addressees have to go through to produce or interpret these instances of anaphoric reference.

In Section 3.1, we saw that component parts of a non-decomposable idiom can be used to refer to a previously introduced discourse entity. In that case, it was argued the speaker reanalyses (and invites the addressee to reanalyse) the idiom in question as decomposable. In other words, where normally the idiom to take the cake would be given the representation in (13) (cf. to kick the bucket in (11)), in example (4b) above, it will be analysed as in (14) (cf. to spill the beans in (10)). 


$$
\begin{aligned}
& \text { IL: } \left.\left.\left(\mathrm{C}_{1}:\left[\left(\mathrm{T}_{1}\right)\left(+\mathrm{id} \mathrm{R}_{1}\right)\right]\left(\mathrm{C}_{1}\right)\right)\right]\left(\mathrm{A}_{1}\right)\right) \\
& \text { RL: } \left.\left(\operatorname{pres~e}_{1}:\left[\left(\mathrm{f}_{1}: \text { take_the_cake }\left(\mathrm{f}_{2}\right)\right)\left(1 \mathrm{x}_{1}\right)\right]\left(\mathrm{f}_{1}\right)\right)\left(\mathrm{e}_{1}\right)\right) \\
& \text { IL: } \left.\left(\mathrm{C}_{1}:\left[\left(\mathrm{T}_{1}\right)\left(+ \text { id } \mathbf{R}_{1}\right)\left(+\mathrm{id} \mathrm{R}_{2}\right)\right]\left(\mathrm{C}_{1}\right)\right)\right] \\
& \text { RL: } \left.\left(\operatorname{pres} \mathrm{e}_{1}:\left[\left(\mathrm{f}_{1}: \operatorname{take}\left(\mathrm{f}_{1}\right)\right)\left(\mathbf{1} \text { rem } \mathrm{e}_{2}: \operatorname{cake}\left(\mathrm{e}_{2}\right)\right)\left(1 \mathrm{x}_{2}\right)\right]\left(\mathrm{f}_{1}\right)\right)\left(\mathrm{e}_{1}\right)\right)^{\mathbf{8}}
\end{aligned}
$$

Unlike in (13), the representation in (14) captures the fact that reference is made to a discourse entity ( $\mathrm{R}_{1}$ at the IL), while the referent itself $\left(\mathrm{x}_{1}\right)$ is represented as a separate unit at the RL. This entity, in turn, is linked to its antecedent (the worst March/April start in club history in (4b)) by means of co-indexation with an element already present in the Contextual Component. Note that since the NP the cake now refers to a state-of-affairs rather than an edible object, it is represented by an e-variable $\left(\mathrm{e}_{2}\right)$.

In all the other types of anaphoric reference discussed, however, anaphoric reference is made to part of a non-decomposable idiom. In these cases we are not dealing with reanalysis, but rather with a process of inference. As we have seen in Section 3.2., the anaphor may be used to refer back to a previously introduced discourse entity (the US nuclear arsenal in (5a), food in (5b)); in that case, however, this reference is mediated by reference to part of the literal scene (the bacon, the cake). In other cases, reference seems to be made only to an element from the literal scene (e.g. a thread and the cake in example (6)). In all these cases, the idioms clearly activate the idiomatic meaning, and, being non-decomposable, they do not introduce any entities into the discourse. So what licences the use of an anaphoric expression?

Here the role of the Contextual Component becomes important. In FDG this component interacts with all levels of representation (Hengeveld \& Mackenzie, 2014). This means that even if no referent or referent set is denoted at the RL, the separate words that make up the idiom are still fed into the Contextual Component from the Morphosyntactic Level (ML). These words activate concepts, and this, in turn, allows the addressee to activate/reconstruct the literal meaning of the idiom. Note that this also accounts for the fact that the literal meaning usually remains backgrounded, as it is normally the conventional meaning, triggered as the higher RL, which precludes the activation of the literal

\footnotetext{
${ }^{8}$ Together with the singularity operator 1 , the operator rem(ote) triggers the demonstrative that.
} 
meaning. Once activated, however, a component part from the literal scene can be promoted to the status of (inferred) discourse referent, and become available as an antecedent.

From here onwards, there are two possibilities. Either the anaphoric reference occurs in a clause that forms a clear variation on the literal meaning of the idiom, in which case the addressee can be expected to infer the intended meaning (e.g. in (6a) where the unravelling of the thread will be taken to mean that the danger is becoming more imminent). In other cases, however, such an inference is not possible; in that case, the addressee will search the Contextual Component for a possible discourse referent in order to establish a second, contextually meaningful anaphoric relation (as in (5a), where this bacon will be understood to refer back to the US nuclear arsenal).

Finally, there are those cases, discussed in 3.2.3., where it could be argued that the speaker creates a new, ad-hoc non-decomposable idiom, e.g. to gnaw the bullet (see (15)). These are not regarded as cases of substitution (after all, there is no separate property (f) at the RL to be replaced), but rather as instances in which a new idiom is created on the basis of a different, but closely related literal scene.

$$
\begin{aligned}
& \text { IL: } \left.\left.\left(\mathrm{C}_{1}:\left[\left(\mathbf{T}_{1}\right)\left(+\mathrm{id} \mathrm{R}_{1}\right)\right]\left(\mathrm{C}_{1}\right)\right)\right]\left(\mathrm{A}_{1}\right)\right) \\
& \left.\mathrm{RL}:\left(\mathrm{e}_{1}:\left[\left(\mathbf{f}_{\mathbf{1}} \text { : gnaw_the_bullet }\left(\mathbf{f}_{2}\right)\right)\left(1 \mathrm{x}_{1}\right)\right]\left(\mathrm{f}_{1}\right)\right)\left(\mathrm{e}_{1}\right)\right)
\end{aligned}
$$

Clearly, however, this is not the only way in which the idiom is manipulated; in addition, the noun phrase has been replaced by the pronoun it. Note, however, that this does affect the interpretation of the construction: the crucial change is clearly in the change of verb. I would therefore like to argue that the verb is the only meaningful element in the realization of this idiom, and that the pronoun, rather than being used anaphorically, functions as a dummy element; i.e. as an element not triggered by anything on the higher two levels, but introduced at the Morphosyntactic Level to fill an obligatory position (in this case the object position; Hengeveld \& Mackenzie, 2008: 347-350).

\section{Conclusion}

In this paper, it has been shown that, unlike what has so far been assumed in the literature, anaphoric reference by or to part of a non- 
decomposable idiom does not necessarily result in wordplay, and that, even if there is a certain degree of wordplay involved, such reference may still be systematic and productive. This means that these occurrences cannot be dismissed as deviations and need to be accounted for in the grammar of a language. Subsequently, some systematic patterns of anaphoric reference by/to parts of non-decomposable idioms have been described, as well as the mechanisms underlying the production and processing of these references, and the various degrees of extra cognitive effort this production and processing requires. In addition, it has been argued that the extra cognitive effort involved is outweighed by the communicative advantages. Finally, an FDG analysis of these anaphoric expressions has been proposed which captures their systematicity and productivity, and which reflects the linguistic and cognitive processes involved in their production and interpretation.

\section{Bibliography}

Chen, Rong. 1990. English demonstratives: A case of semantic expansion. Language Sciences 12(2/3): 139-153.

Davies, Mark. 2008. COCA: The corpus of contemporary American English (1990-2015). http://corpus.byu.edu/coca.

Davies, Mark. 2016. NOW Corpus (News on the Web) (2010-). https://corpus. byu.edu/now/.

Diessel, Holger. 1999. Demonstratives. Form, Function and Grammaticalization. Amsterdam / Philadelphia: John Benjamins.

Dik, Simon C. 1992. Idioms in a Functional Grammar. Linguistica computazionale 6: 241-266.

Glucksberg, Sam. 1993. Idiom meanings and allusional content. In Cacciari, Cristina \& Tabossi, Patrizia (ed.) Idioms: Processing, Structure, and Interpretation. Hillsdale NJ: Laurence Erlbaum, 3-26.

Glucksberg, Sam. 2001. Understanding Figurative Language: from Metaphors to Idioms. Oxford: Oxford University Press.

Hengeveld, Kees \& Mackenzie, J. Lachlan. 2008. Functional Discourse Grammar: A Typologically-Based Theory of Language Structure. Oxford: Oxford University Press.

Hengeveld, Kees \& Mackenzie, J. Lachlan. 2014. Grammar and context in Functional Discourse Grammar. Pragmatics 24(2): 203-227.

Keizer, Evelien. 2016. Idiomatic expressions in Functional Discourse Grammar. Linguistics 54(5): 981-1016. 
Langlotz, Andreas. 2006. Idiomatic Creativity: A Cognitive-Linguistic Model of Idiom-Representation and Idiom-Variation in English. Amsterdam: John Benjamins.

Lyons, John. 1977. Semantics (2 vol.). Cambridge: Cambridge University Press.

McClure, Scott. 2011. Modification in non-combining idioms. Semantics and Pragmatics 4: 1-7.

Nunberg, Geoffrey; Sag, Ivan A. \& Wasow, Thomas. 1994. Idioms. Language 70(3): 491-538.

Vega Moreno, Rosa E. 2007. Creativity and Convention: the Pragmatics of Everyday Figurative Speech. Amsterdam: John Benjamins. 
